\title{
Implementing a Mobile Application for Spontaneous Peak Shaving of Home Electricity
}

\author{
Keisuke Tokuda, Shinsuke Matsumoto, Masahide Nakamura \\ Graduate School of System Informatics, Kobe University \\ 1-1 Rokkodai, Nada, Kobe, Hyogo, 657-8501 Japan \\ Email: tokuda@ws.cs.kobe-u.ac.jp, \{shinsuke, masa-n\}@cs.kobe-u.ac.jp
}

\begin{abstract}
Electricity peak shaving is a promising approach to energy saving at home. The conventional peak shaving has been conducted in an automatic and system-centric approach, using the emerging home energy management systems (HEMS). However, for more sustainable energy-saving, it is also important to develop a human-centric approach, which encourages residents to perform energy-saving behaviors by themselves.

In this paper, we present a smartphone application, named Peak Cutter, which assists home users to perform spontaneous peak shaving. Cooperating with a home network system, Peak Cutter monitors electricity demand in a house, and notifies the user via a smartphone when the demand exceeds a threshold. The user then checks the current energy consumption of each home appliance, and can remotely turn off some appliances to shave the peak. We have also conducted an experiment, where five subjects tried to save energy of our laboratory using Peak Cutter. It was shown that a certain amount of energy was reduced within the one-week experiment, and that Peak Cutter promoted energy-saving attitudes of most of the subjects.
\end{abstract}

Keywords-energy-saving, peak shaving, human interface, smartphone, home network system

\section{INTRODUCTION}

Energy saving has become the most urgent environmental problem to be addressed by international society. The company BP p.l.c., one of the world's leading international oil and gas industries, reported [1] that the global energy consumption is 1.5 times as large as two decades ago. Lawrence Berkeley National Laboratory reported [2] that household energy consumption accounted for $21 \%$ of all domestic energy consumption in the United States. Also in Japan, energy consumption continues to increase [3] and the household energy consumption has become double within the last 30 years[4]. This is because of the increase in the number of households, the spread of home appliances and the size and rich features of the appliances, despite its own energy efficiency gains.

A number of studies have been conducted to improve electric energy efficiency in a household from an automatic and system-centric approach [5][6][7]. Examples include: improving the energy efficiency of an air-conditioning system by using thermal insulation materials [5], a smart home (or home network system) with HEMS (home energy management system) which improves total energy efficiency by automatically orchestrating some appliances [6][7], energy-efficient appliances with ICT-based automation and optimization. We call these conventional energy-saving method system-centric approaches, in the sense that they achieve the energy saving with systems.

In contrast to the system-centric approach, we consider human-centric approach which tackles the household energy problem with residents. This approach encourages residents to perform energy-saving behaviors, by raising individual awareness of energy saving. A well-known human-centric approache is visualization of energy consumption. In general, it is difficult to figure out how much energy is used every day. The visualization system can tell us the amount of energy we are using, as well as the cost that has been paid. The humancentric approach should be used together with the systemcentric approach to save further energy.

A challenge in the human-centric approach is that it requires strong motivation of the users. It basically relies on human effort. The residents may give up continuing the energysaving behaviors if the operations are complicated. The key to promote the human-centric approach is how to encourage residents with a simple and interesting mechanism.

The peak shaving and load shifting of home electricity are known to be effective technique to reduce electricity consumption. They reduce or shift the amount of energy consumption during peak demand periods to lower demand periods. Traditionally, they have been implemented as systemcentric solutions. However, we consider that the peak shaving and the load shifting are quite compatible with human-centric approach. This is because the residents can perform their own peak shaving, according to their preferences and life styles.

In this paper, we propose a smartphone application, named Peak Cutter, which assists home users to perform spontaneous peak shaving. Cooperating with our developing home network system [8], Peak Cutter monitors electricity demand in a house, visualizes energy consumption of each appliance and notifies a user via a smartphone when the demand exceeds a threshold. The user then checks the current energy consumption, and can remotely turn off some appliances to shave the peak.

We have conducted an experiment, where five subjects tried to save energy of our laboratory using Peak Cutter. It was shown that a certain amount of energy was reduced within the one-week experiment. We have also interviewed the subjects about Peak Cutter. The interview results show that Peak Cutter promoted energy-saving attitudes of most of the subjects. 


\section{PRELIMINARIES}

\section{A. Home Network System (HNS)}

A home network system (HNS) orchestrates household appliances, sensors and house equipments via network, in order to achieve value-added services. We have been developping a real HNS called CS27-HNS[8]. CS27-HNS adopts the serviceoriented architecture (SOA). Each networked appliance exhibits its features as Web services (Web-API). The Web-API allows users or external agents to monitor and control the device by platform-independent protocols (SOAP or REST). CS27-HNS also integrates a smart meter, by which energy consumption of every appliance is measured and stored to a database in XML format.

Within CS27-HNS, we have been developing various applications. One application is the energy consumption lookback service [9]. This service monitors the consumption of each appliance and visualizes the statistics with environment contexts and appliance operations. This service will be used in our experimental evaluation in Section IV.

\section{B. Classification of Energy Saving}

In our study, we classify energy-saving approaches into two points of view: one is system-centric approach and the other is human-centric approach. The system-centric approach is to improve coefficient of performance (COP) by electric appliances themselves. Example appliances include low-energy appliances (e.g., LED light, liquid crystal television), and energyaware appliances that automatically behave efficiently using environmental sensors (e.g., motion-sensing lights). Moreover, the IT systems that integrate multiple appliances for efficient energy management such as SmartGrid [10], HEMS [11] come onto market. In a system-centric approach, the system basically takes initiative to save energy. The energy-saving mechanism is automatically executed without human effort. However, it does not consider the user's context.

The human-centric approach aims to promote energy-saving attitudes of residents by themselves. This approach improves their awareness of environmental issues through visualization of consumption, learning from energy-saving guidelines, and so on. Some agencies and companies exhibit various guidelines, explaining how to use appliances efficiently [12]. Japanese National Policy Unit in Cabinet Secretariat has reported that energy visualization could promote energy-saving attitudes of residents and could reduce it about $10 \%$ [13].

Although the technologies prefer to promote system-centric approaches, we consider that the balance of system-centric and human-centric approaches is important to achieve sustainable energy-saving behaviors. The human-centric approach strongly depends on motivation of the residents. So complicated operations decrease the quality of life. It is necessary to provide easy and interesting mechanisms that assist residents to perform energy-saving behaviors.

\section{Approaches of Energy Saving}

Reduction of total energy demand is most popular and efficient approach for all common environmental energy-saving (e.g., water, gas, electricity). The guidelines described in Section II-B contribute to the total energy reduction approach. With respect to the electric energy, it is also efficient to reduce peak demand of electrical energy. Since it is difficult to store electric energy, electric power companies supply the energy based on calculation of maximum demand. Therefore, reducing the peak demand significantly contributes to the large reduction of energy consumption.

The peak demand reduction is further categorized into peak shaving and load shifting. The peak shaving is an approach to reduce the amount of energy consumption during peak demand periods. The load shifting is to shift the amount of consumption from peak demand periods to off-peak periods. Traditionally, the peak shaving and load shifting are both system-centric solutions built in HEMS or Smart Grid. However, we consider that these approaches are compatible with human-centric approach. This is because residents can perform energy saving according to individual circumstances.

\section{Research Goal and Scope}

The goal of this paper is to promote human-centric approach in each household. We propose an energy-saving method that combines the peak shaving with a human-centric approach. Specifically, we address the following two goals in this paper.

- Goal G1: Encourage residents to perform energy saving spontaneously. To promote spontaneous and sustainable energy-saving by residents, the effort for energysaving should be as small as possible. For this, it is necessary to visualize energy consumption and to notify in peak demands.

- Goal G2: Allow residents to check and control home appliances anytime and anywhere. To achieve energysaving by residents, they should be able to operate an appliance easily. We also think that residents should become to be able to control appliances easily anytime and anywhere.

\section{Peak Cutter: Proposed System}

\section{A. Overview}

To achieve the goals, we propose an an application called Peak Cutter in this paper. Peak Cutter is implemented as a smartphone application, so that individual residents can conduct energy-saving operations easily and quickly. Every resident can check when a peak power demand occurs and how much energy is consumed by every appliance. The resident also can remotely operate home appliances when the peak demand occurs. More specifically, Peak Cutter implements the following three features by cooperating with our home network system (CS27-HNS, see Section II-A).

- Power Consumption Graph: Visualizes energy consumption of every home appliance.

- Peak Notification: Notifies a user of peak demand periods.

- Remote Control: Allows a user to turn off energywasting appliances. 


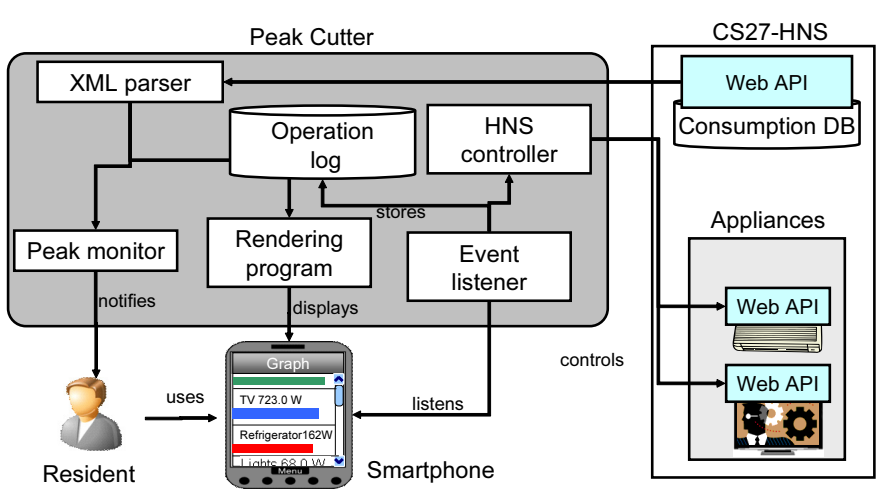

Fig. 1. Architecture of Peak Cutter

\section{B. Architecture of Peak Cutter}

Figure 1 shows the overall architecture of Peak Cutter. CS27-HNS is periodically recording power consumption data of every appliance in Consumption DB. Peak Cutter accesses Web-API to retrieve the power consumption data in an XML format. XML parser parses the consumption data, and passes the data to Peak monitor and Rendering program.

For a given consumption data, Peak monitor checks if the total amount exceeds the pre-defined peak value. When the total consumption exceeds a threshold, Peak monitor notifies the resident by vibration and sound.

Rendering program depicts Power Consumption Graph on a smartphone. When the resident presses the graph of the appliance, Peak Cutter shows the home controller screen of the appliance. Event listener detects mobile operations by the resident and notifies HNS controller. Then, this controller controls the appropriate appliance via network with the WebAPI. At this time, the listener stores it in Operation log.

In the following sections, we specifically explain how a user operate Peak Cutter to perform human-centric peak shaving.

\section{Checking Power Consumption Graph}

Figure 2(a) shows a screen of user setting. In this screen, a user registers his/her name, age, sex, user type (waste or save) and language (Japanese or English). Once the user information is set, Peak Cutter depicts Power consumption graph as shown in Figure 2(c). Power consumption graph shows the current electricity consumption of every appliance in a bar chart. The screen also shows the total consumption, a peak threshold, a user type and date. A user can check the current consumption and threshold promptly. The graph is updated periodically ( 3 every second by default). Therefore, a well-motivated user can check it frequently to perform energy-saving behaviors before the total consumption exceeds a threshold. In the current implementation, the threshold is automatically determined, depending on the user type specified in the user setting.

Power consumption graph can be customized for convenience of the user, as follows:

- Sort appliances in power consumption.

- Refresh the graph manually.

- Exclude appliances that are not interested.

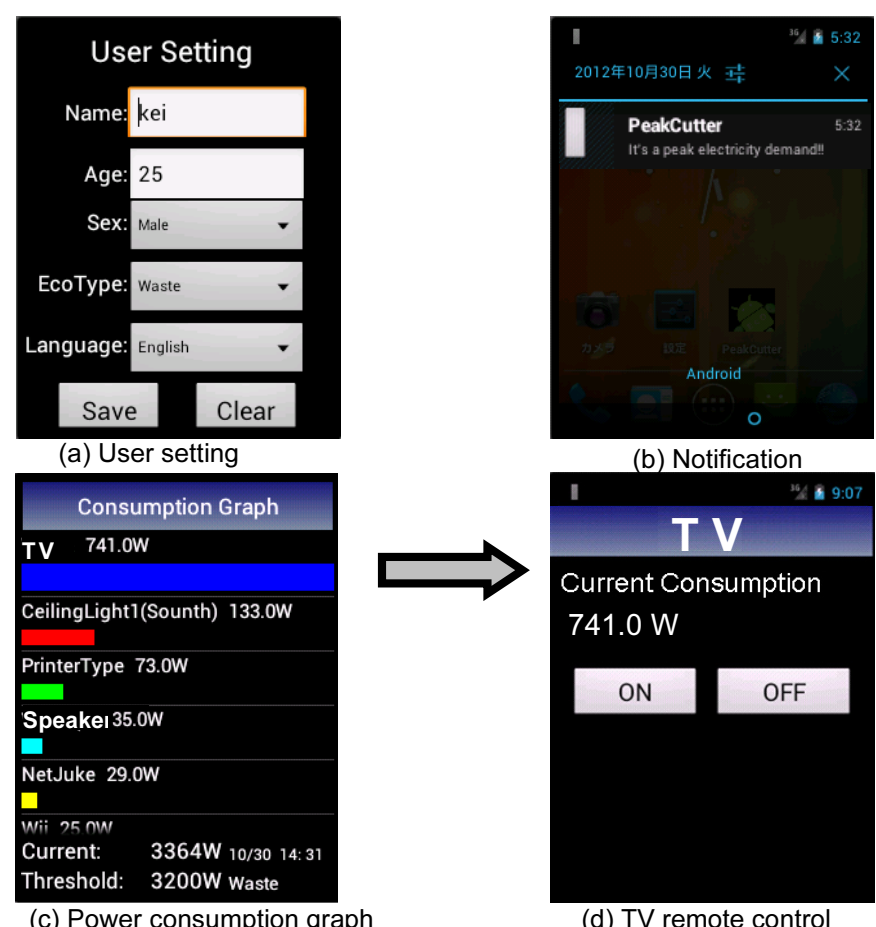

(d) TV remote control

Fig. 2. Screen-shots of Peak Cutter

\section{Notifying Electricity Peak Demand Periods}

Peak Cutter periodically monitors the total consumption as a background process of a smartphone. When the current energy consumption exceeds a threshold value, Peak Cutter notifies the user of the peak by using a sound, vibration and a notification screen appears as shown in Figure 2(b).

Upon the notification, the user taps the message to pop up Power consmption graph in Figure 2 (c). The user can check which appliances are consuming much electricity. Since they should perform energy-saving only at peak demand periods, we consider that they can perform peak shaving without burden. When a user tap a graph of an appliance, the screen is changed to Remote Control Screen.

\section{E. Remote Control of Applicances}

For example, if a resident presses the graph item TV in Figure 2(c), Peak Cutter moves into TV remote screen as shown in Figure 2(d). Thus, the user can switch back and forth the remote control screen and the graph screen, easily and quickly.

In CS27-HNS, API of household appliances are deployed as Web services. Therefore Peak Cutter can remotely control appliances via network. Figure 2(d) shows TV remote control. In this screen, the resident can check the current consumption and turn on or off the appliance. Moreover, if the appliance is used by other users, the user can notify them of turning off by using a voice notification service. This service plays the audio alert, such as "Please turns off the PC." As a result, the users can perform peak shaving from anywhere when they receive the notification. 


\section{F. Implementation}

Peak Cutter has been implemented by an Android application. The code was written in Java with Android SDK, comprising about 3,300 lines of code. Development effort was about two man-months.

\section{EXPERIMENTAL EVALUATION}

\section{A. Experiment Settings}

We have conducted an experiment, where subjects tried to save energy of our laboratory. The objective of the experiment is to evaluate the proposed Peak Cutter from the following two viewpoints.

- Capability of Peak Cutter to motivate energy saving: Can Peak Cutter promote energy-saving attitudes of residents and contribute to peak shaving?

- Usability of Peak Cutter for sustainable operations: Is Peak Cutter easy and interesting enough to perform sustainable energy-saving behaviors?

Total five subjects participated the experiment, consisting of two graduate students and three undergraduates. Two of the five were interested in energy saving very much. Other two had wasteful habits and did not like to tolerate uncomfortable environments. The last one was not especially interested in saving or wasting energy. They were all male in their 20's.

The experiment was conducted in our CS27-HNS experimental room (see Section II-A). We installed Peak Cutter on the following smartphones: Android Dev-Phone One (Android 1.6), ICONIA TAB A100 (Android 3.2), CH-AND7000 (Android 4.03), REGZA Tablet A570 (Android 4.03), and handed them to the subjects. The appliances used in the experiments were a plasma TV (Panasonic VIERA TH-58PZ800), a fan (Doshisha GIR-350), ceiling lights (Panasonic HHFZ5810) and an aroma diffuser (Sterling White 6640).

Every subject tried to save energy using Peak Cutter for a week from July 23th until 29th, 2012. We measured the energy-saving effort taken for each subject. We also interviewed the subjects how the energy-saving behaviors were from the above two viewpoints.

\section{B. Experimental Results}

Figure 3 shows daily energy consumption of our experimental room in July 2012. In the figure, a gray box represents a week from July 23th to 29th, where the experiment was conducted. The total power consumed during the week was $376 \mathrm{kWh}$. Let us see another week from July 16th to 23th, which is the previous week of the experiment. The total power consumption of the previous week was $387 \mathrm{kwh}$. By comparing the two values, we can see that Peak cutter was able to shave $11 \mathrm{kwh}$ of the weekly power consumption.

The value of $11 \mathrm{kwh}$ might not be significant. However, the comparison is not that simple actually. This is because the power consumption heavily depends on various environment factors such as weather, the number of people, and events in the room. For a fair comparison, the two weeks must follow the same environmental setting, which is not realistic.

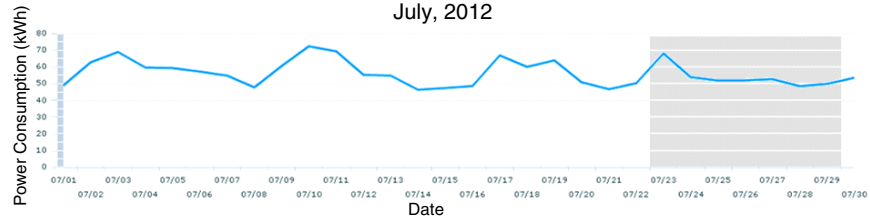

Fig. 3. Energy consumption in experimental room in July 2012 (kWh)
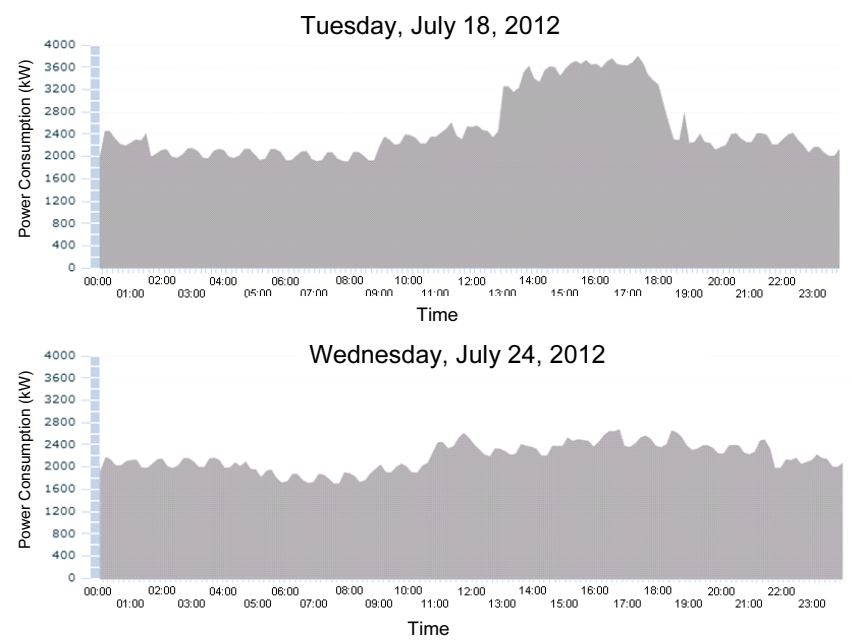

Fig. 4. Comparison of two days with and without Peak Cutter (kW)

Therefore, we have picked up two days July 18th and July 24th, which had quite similar environmental factors. Table I shows environmental logs of $1 \mathrm{pm}$ of the two days, which were recorded by sensors of CS27-HNS. We can see the similarity in the measurements of the two days. Note that the experiment was conducted in 24th, but NOT in 18th.

For these two days, now we make a comparison. The total power consumption of 18th was $60 \mathrm{kWh}$, whereas that of 24 was $53 \mathrm{kWh}$. This result shows that Peak Cutter was able to achieve $10 \%$ reduction of the daily power consumption. The ratio was satisfactory for us, and we say that Peak Cutter surely contributed to the reduction of total energy.

Next, we compare the two days in details, in order to see if Peak Cutter contributed to peak shaving. Figure 4 represents two time-series data of power consumption on July 18th and 24 th, respectively. From the figure, it can be seen that the shape of the graph of July 24th is much flatter than that of July 18th. We can see that the peak of power consumption on July 18 th is about $3,800 \mathrm{~kW}$, and the peak on July 24 th is about 2,700 $\mathrm{kW}$. This result shows that Peak Cutter contributed to shaving $29 \%$ of the peak value.

Figure 5 shows the statistics of operation logs recorded by Peak Cutter. The horisontal axis represents five subjects A, B, $\mathrm{C}, \mathrm{D}$ and $\mathrm{E}$, each of whom is associated with an energy-saving attitude. The vertical axis represents the number of operations performed by a subject to save the energy. As shown in Figure 5 , the operations used by the five subjects were "turn off TV", "turn off lights" and "voice notification service". They didn't use the aroma because there was no opportunities to use it.

The statistics show that subjects B and E operated Peak 
TABLE I

ENVIRONMENTAL MEASUREMENTS OF TWO DAYS

\begin{tabular}{|rr|rrrrr|rrrr|}
\hline & & \multicolumn{6}{|c|}{ Inside Room } & \multicolumn{4}{c|}{ Outside } \\
Date & Time & Temperature & Humidity & Brightness & People & Airflow & Temperature & Humidity & Pressure & Weather \\
\hline \hline $2012 / 7 / 18$ & $13: 00: 00$ & 26.6669 & 38 & 278 & 5 & 0.209 & 30.44464 & 49.0008 & 100 & partly cloudy \\
$2012 / 7 / 24$ & $13: 00: 00$ & 26.44468 & 36 & 251 & 5 & 0.11 & 30.88908 & 54.3376 & 99.75 & partly cloudy \\
\hline
\end{tabular}

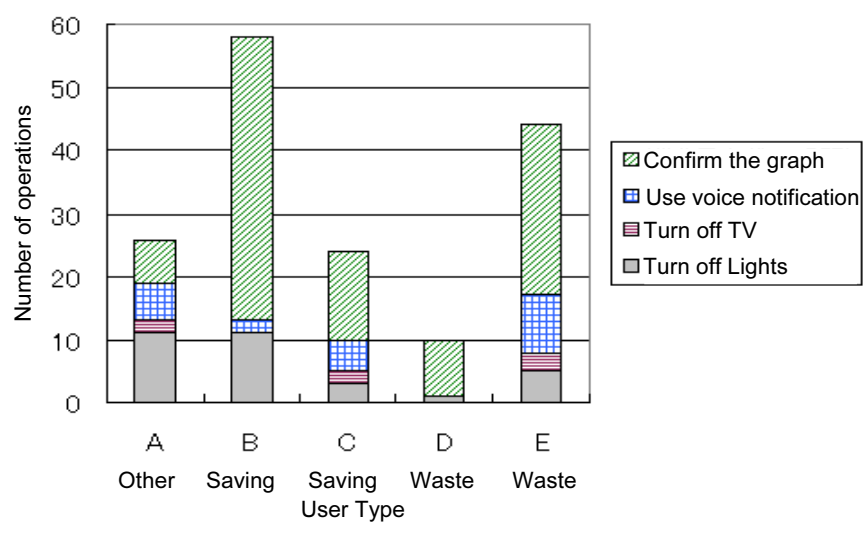

Fig. 5. Operational log of the subjects in Peak Cutter (number of times)

Cutter many times compared with other three. Especially, subject $\mathrm{B}$, who liked energy-saving, checked the energy consumption very frequently. Subject E performed spontaneous energy-saving despite of the fact that he used to have wasting habits. The total numbers of operations of subject $\mathrm{A}$ and $\mathrm{C}$ were less than those subject B and E. Interestingly however, subject A turned off appliances most frequently. Subject C used the voice notification service many times. However, he did not very often turn off the appliances. Subject D seldom operated Peak Cutter, as he might not want to be bothered.

Tables II represents the result of a questionnaire performed in the subsequent interview. The questionnaire asked attitudes of subjects towards energy-saving behaviors, as well as satisfaction of Peak Cutter. Table III summarizes comments from the subjects. They include positive and negative comments and opinions for Peak Cutter and experiments.

\section{Discussion}

We evaluate Peak Cutter from the two viewpoints.

\section{(1) Capability to motivate energy-saving behaviors}

In the interview, we obtained mostly positive opinions from the subjects. For the question Q1 in the questionnaire, all the subjects have performed some energy-saving behaviors. Three of them said were well motivated by Peak Cutter. From the question Q2, only one subject considered energy saving to be tedious. We can see positive comments in Table III, including "it was useful to control appliances from anywhere", "I liked to check the consumption graph, since it was interesting to see how I'm using appliances", and "I found it useful to smartphone to perform energy-saving behaviors".

The average number of Peak Cutter operations executed per a day varied from three to eight times. Although subject $\mathrm{E}$ had originally wasteful characteristics, he operated Peak Cutter
TABLE II

RESULT OF QUESTIONNAIRE

\begin{tabular}{|c|c|c|}
\hline \multicolumn{3}{|c|}{ Q1: How did you do energy saving with PeakCutter? } \\
\hline $\begin{array}{c}\text { Did when I want } \\
2 \\
\end{array}$ & $\begin{array}{c}\text { Did whenever I can } \\
2 \\
\end{array}$ & $\begin{array}{c}\text { Did willingly } \\
1 \\
\end{array}$ \\
\hline \multicolumn{3}{|c|}{ Q2: Were energy-saving operations burdens for you? } \\
\hline $\begin{array}{c}\text { Yes } \\
1\end{array}$ & $\begin{array}{c}\text { Not very } \\
2\end{array}$ & $\begin{array}{c}\text { Not at all } \\
2\end{array}$ \\
\hline \multicolumn{3}{|c|}{ Q3: How should PeakCutter assist you? } \\
\hline $\begin{array}{c}\text { Be more automatic } \\
4\end{array}$ & $\begin{array}{c}\text { Be more manual } \\
1\end{array}$ & $\begin{array}{c}\text { As it is } \\
0\end{array}$ \\
\hline \multicolumn{3}{|c|}{ Q4: Was the notification feature effective? } \\
\hline $\begin{array}{c}\text { Not effective } \\
2\end{array}$ & $\begin{array}{c}\text { Not too bad } \\
1\end{array}$ & $\begin{array}{c}\text { Very effective } \\
2\end{array}$ \\
\hline \multicolumn{3}{|c|}{ Q5: Was the remote control feature useful? } \\
\hline $\begin{array}{c}\text { Not useful } \\
0\end{array}$ & $\begin{array}{c}\text { Not very } \\
1\end{array}$ & $\begin{array}{c}\text { Useful } \\
4\end{array}$ \\
\hline \multicolumn{3}{|c|}{ Q6: Was Peak Cutter useful for you? } \\
\hline $\begin{array}{c}\text { Not useful } \\
1\end{array}$ & $\begin{array}{c}\text { Not very } \\
1\end{array}$ & $\begin{array}{l}\text { Useful } \\
3\end{array}$ \\
\hline \multicolumn{3}{|c|}{ Q7: Were you tired of the experiment? } \\
\hline $\begin{array}{c}\text { Yes } \\
2\end{array}$ & $\begin{array}{c}\text { Unsure } \\
0\end{array}$ & $\begin{array}{c}\mathrm{No} \\
3\end{array}$ \\
\hline
\end{tabular}

TABLE III

COMMENT FROM SUBJECTS

\begin{tabular}{l}
\hline Please give us comments about Peak Cutter \\
\hline It was useful to control appliances from anywhere. \\
I liked to check the consumption graph. \\
The notification is annoying as I don't want to turn off anything. \\
I wanted to set a threshold of peak demand freely. \\
Controllable applicances are so limited. I want to controll more. \\
\hline
\end{tabular}

as much as 44 times in total, which is the second most in the subjects. Thus, we consider that Peak Cutter can promote energy-saving behaviors to some extent.

Through the subsequent investigation, there is no significant correlation between the energy-saving attitudes and the number of Peak Cutter operations. Thus, the individual preferences to the application are the strong factor.

\section{(2) Usability for sustainable operations}

From the result of the experiment, it was shown that Peak Cutter could promote residents successfully to perform total energy saving and peak shaving. However, we found that there is still room for improvement in Peak Cutter especially with respect to usability.

As shown in Figure 5, subject D hardly performed any energy-saving operations. Also as seen in from Q2 to Q7 in table III, some subjects said that they were uncomfortable and felt burden on the notification or energy-saving operations. 
Especially it is interesting to see Q3. Most subjects thought that Peak Cutter should be more automatic for easy operations.

Therefore, to achieve sustainably peak shaving by all residents, it is necessary to assist them to do it without discomfort and burden. We also found that subjects wanted to customize the notification method, as well as assist level based on the preferences. We will implement the personalized features in the future development.

\section{RELATED WORK}

Ying-Xun et al. [14] proposed a system that promotes energy-saving attitudes by visualizing energy consumption of home appliances using a smart meter. Residents can monitor their appliances in a real picture and turn off the appliances when there is no one in the room. This study has the same goal as ours in terms of assisting energy saving behaviors. However, it is different in that it focuses the reduction of total energy consumption. On the other hand, our study tries to reduce the consumption in peak demand periods.

Jinsoo et al. [15] implemented an energy visualization and remote control system using ZigBee. The unique point is that it tries to reduce standby electricity. This study is similar to ours in that it promotes energy saving by remote control and visualizing energy consumption with HEMS. However, it differes in that we focus on the human-centric approach. In our study it is a human resident who turns off the wasteful appliances. This is to motivate people for energy saving.

Recently, there is an increasing number of studies about the load shifting. Sean et al. [16] proposed Least Slack First (LSF) which performs load shifting automatically without residents burden. LSF disperses energy consumption of peak demand periods by avoiding simultaneous utilization of appliances automatically. By adopting this approach in our study, we would expect more efficient energy-saving.

The common goal of these related work is to save energy although their details are different from each other. We consider that these studies do not conflict with Peak Cutter, and that they should be complementary to achieve more efficient energy saving.

\section{CONCLUSION}

In this paper, we have proposed a smartphone application, named Peak Cutter, which assists home users to perform spontaneous peak shaving. Cooperating with a home network system, Peak Cutter monitors electricity demand in a house, visualizes energy consumption of each appliance and notifies the user via a smartphone when the demand exceeds a threshold. The user then checks the usage of energy for every appliance, and remotely turns off some appliances.

We have conducted an experiment, where five subjects tried to save energy of our laboratory using Peak Cutter. It was shown that a certain amount of energy was reduced within the one-week experiment. The interview results show that Peak Cutter promote energy-saving attitudes of most of the subjects.

Basically, peak shaving should be performed not on single house but on city or country. In this paper, we developed
Peak Cutter for single home use. In our future work, we will extend Peak Cutter to check society-wide peak demand using ICT-based smart city infrastructure. We will also have plan to extend Peak Cutter features so as to provide an assist adapted individual preference for more sustainability and spontaneously energy-saving by all residents.

\section{ACKNOWLEDGMENT}

This research was partially supported by the Japan Ministry of Education, Science, Sports, and Culture [Grant-in-Aid for Scientific Research (C) (No.24500079), Scientific Research (B) (No.23300009)], and Kansai Research Foundation for technology promotion.

\section{REFERENCES}

[1] BP, “Energy outlook 2030," http://www.bp.com/liveassets/bp_internet/ globalbp/STAGING/global_assets/downloads/O/2012_2030_energy_ outlook_booklet.pdf.

[2] Lawrence Berkeley National Laboratory, "Global energy," http://newscenter.lbl.gov/wp-content/uploads/majumdar-globalenergy_ lbl2.pdf.

[3] Agency for Natural Resources and Energy, "Energy conservation policies of japan," http://www.enecho.meti.go.jp/policy/saveenergy/save01/ genjo_English.pdf.

[4] Agency for Natural Resources and Energy, "Energy in japan 2010," http://www.enecho.meti.go.jp/topics/energy-in-japan/english2010.pdf.

[5] M. A. Aktacir, O. Büyükalaca, and T. Yilmaz, "A case study for influence of building thermal insulation on cooling load and air-conditioning system in the hot and humid regions," Applied Energy, vol. 87, no. 2, pp. 599-607, 2010.

[6] S. Karnouskos, A. Weidlich, J. Ringelstein, A. Dimeas, K. Kok, C. Warmer, P. Selzam, S. Drenkard, N. Hatziargyriou, and V. Lioliou, "Monitoring and control for energy efficiency in the smart house," Energy-Efficient Computing and Networking, vol. 54, pp. 197-207, 2011.

[7] G. Will, A. Anna, and L. Alberto, "Smart meter devices and the effect of feedback on residential electricity consumption: Evidence from a natural experiment in northern ireland," FEEM Working Papers, vol. 54, pp. 197-207, 2011.

[8] M. Nakamura, A. Tanaka, H. Igaki, H. Tamada, and K. Matsumoto, "Constructing home network systems and integrated services using legacy home appliances and web services," Int'l J. of Web Services Research, vol. 5, no. 1, pp. 82-98, 2008.

[9] H. Igaki, H. seto, M. Fukuda, S. Matsumoto, and M. Nakamura, "Implementation and evaluation of a looking back service for power consumption behavior (in japanese)," IEICE Trans., vol. J95-D, no. 4, pp. 778-789, 2012.

[10] S. M. Amin and B. Wollenberg, "Toward a smart grid:power delivery for the 21st century power and energymagazine," IEEE Power and Energy Magazine, vol. 3, no. 5, pp. 34-41, 2005.

[11] A. Rossello-Busquet and J. Soler, "Towards efficient energy management: Defining hems and smart grid objectives," International Journal On Advances in Telecommunications, vol. 4, no. 3, pp. 249-263, 2012.

[12] The KANSAI electric power Co. Inc., "Enjoy energy saving life," http: //www1.kepco.co.jp/sho-ene/top.html, (in Japanese).

[13] National Policy Unit, "Measures of the demand gap resolution,” http://www.npu.go.jp/policy/policy09/pdf/20120502/shiryo3.pdf, (in Japanese).

[14] Y.-X. Lai, J. J. P. C. Rodrigues, Y.-M. Huang, Hong-GangWang, and C.-F. Lai, "An intercommunication home energy management system with appliance recognition in home network," Mobile Networks and Applications, vol. 17, pp. 85-89, 2012.

[15] J. Han, C.-S. Choi, and I. Lee, "More efficient home energy management system based on zigbee communication and infrared remote controls," IEEE Transactions on Consumer Electronics, vol. 57, pp. 132-142, 2011.

[16] S. Barker, A. Mishra, D. Irwin, P. Shenoy, and J. Albrecht, "Smartcap: Flattening peak electricity demand in smart homes," in Int't Conf. on Pervasive Computing and Communications, 2012, pp. 67-75. 